\title{
Shaping the international logistics strategy in the internationalisation process
}

\author{
Gino Marchet \\ Department of Management, Economics and Industrial Engineering, \\ Politecnico di Milano, \\ Via Raffaele Lambruschini 4/B, 20156, Milan, Italy \\ E-mail: gino.marchet@polimi.it
}

\section{Marco Melacini}

Department of Management, Economics and Industrial Engineering, Politecnico di Milano,

Via Raffaele Lambruschini 4/B, 20156, Milan, Italy

E-mail: marco.melacini@polimi.it

\section{Sara Perotti}

Department of Management, Economics and Industrial Engineering, Politecnico di Milano,

Via Raffaele Lambruschini 4/B, 20156, Milan, Italy

E-mail: sara.perotti@polimi.it

\section{Elena Tappia*}

Department of Management, Economics and Industrial Engineering, Politecnico di Milano,

Via Raffaele Lambruschini 4/B, 20156, Milan, Italy

E-mail: elena.tappia@polimi.it

* Corresponding author

This is a post-peer-review, pre-copyedit version of an article published in International Journal of Supply Chain and Operations Resilience. The final authenticated version is available online at: https://doi.org/10.1504/IJSCOR.2016.075914

\begin{abstract}
Internationalisation has increasingly become a strategic issue for companies. Ample evidence confirms the key role of logistics in supporting the company internationalisation process, especially in today's context characterised by growing demand in speed and flexibility. Setting the logistics strategy in line with corporate objectives for each export area over time is crucial and represents a challenge for logistics directors worldwide. The aim of this paper is to address this gap by providing empirical-based evidence on how the international logistics strategy should be shaped accordingly with company internationalisation choices. The
\end{abstract}


research is based on case studies with a sample of 14 exports areas of 6 companies. Results offer a new approach with respect to previous contributions that studied specific logistics issues separately. From a practical viewpoint, managers can benefit from a full picture of both the variables to be set up and the potential alternatives to be selected when designing the international logistics strategy.

Keywords: Internationalisation process; International Logistics Strategy; Multiple Case Studies

Biographical notes: Elena Tappia is a Research Fellow at Politecnico di Milano (Italy), Department of Management, Economics and Industrial Engineering. She held her Master of Science in Management, Economics and Industrial Engineering cum laude at Politecnico di Milano in 2010. In 2014, she gained her PhD cum laude at Politecnico di Milano, where she currently lectures and undertakes research on logistics. She is author of a number of publications, including contributions in international scientific journals and international conference proceedings. Her main current research interests include automated warehousing systems, logistics and supply chain management.

Marco Melacini is an Associate Professor at Politecnico di Milano (Italy), Department of Management, Economics and Industrial Engineering. He currently lectures on Logistics. Since 2007 he has been director of the Physical Distribution course for executives at MIP, the Politecnico di Milano Business School. He was involved in over 20 research/technology transfer projects, and since 2011 he has been scientific responsible for the Contract Logistics Observatory, at Politecnico di Milano. His current research interests include: warehousing and material handling system design, global logistics networks, supply chain risk management and supply chain sustainability. He is author of over 100 publications, including contributions in international scientific journals, international books and conference proceedings.

Sara Perotti is an Assistant Professor at Politecnico di Milano (Italy), Department of Management, Economics and Industrial Engineering. She gained her M.Sc. in Mechanical Engineering, major in Transportation with highest honours at Politecnico di Milano. In 2010 she gained her PhD at Politecnico di Milano, where she currently lectures and undertakes research on logistics, warehousing and transport. Her present research fields are warehousing and material handling system design, information and communication technology (ICT) for freight transport, and supply chain sustainability. She is a member of the Editorial Advisory Board of the International Journal of Physical Distribution \& Logistics Management, and she is reviewer for a number of international scientific journals. She is author of numerous publications, including contributions in international scientific journals and international conference proceedings. 
Gino Marchet is a full Professor at Politecnico di Milano (Italy), Department of Management, Economics and Industrial Engineering since 2004. He currently lectures on Logistics. He is director of the "Warehouse design" executive course at MIP, Politecnico di Milano business school. Since 2003 he has been director of the Material Handling Observatory at Politecnico di Milano, and he is currently Director of the Contract Logistics Observatory, whose aim is to investigate logistics outsourcing features and trends. He is a member of the Editorial Advisory Board of the International Journal of Physical Distribution \& Logistics Management and he is reviewer for a number of international scientific journals. He has written and contributed to numerous textbooks and academic papers.

\section{Introduction}

In recent years, the international trade has grown significantly. The World Trade Report (WTO) 2014 suggests that the percentage of export growth from the United States and European Union to the rest of the world increased in the period 2010Q1-2014Q1 of about 18\% and 25\%, respectively. In particular, the export rates to the fastest growing regions such as Middle East and Asia are quite significant (4.5\% and $4.1 \%$, respectively). Technological advances in transport and communication systems and the reduction in trade barriers are considered as the most significant factors that may have contributed to this remarkable international trade expansion in the last thirty years (e.g. Straube et al., 2008).

Today every company is somehow part of one (or more) global supply chain(s). Companies may face the international challenge by tackling several issues, such as foreign direct investments (FDI), international sales and marketing, international sourcing and logistics. The academic literature firstly focused on explaining the reasons behind company internationalisation (e.g. Hennart, 1982) and then used the above-mentioned issues related to the international challenge as the perspectives to study such process. Previous contributions widely agree that the growth in the international trade implies that supply chains become more international and complex (Monczka and Trent, 2006), and that logistics represents the backbone of the internationalisation process (Peterson et al., 2000; Straube et al., 2008). The important impact of the logistics performance on the customer service is also recognised (e.g. SimchiLevi et al., 2009; Straube et al., 2008).

From a practitioners' perspective, there is a close relationship between company internationalisation choices and logistics processes. On the one hand, logistics is a key enabler for company internationalisation. On the other hand, internationalisation contributes to increase logistics network complexity. Especially in today's context characterised by growing demand in speed and 
flexibility, companies are aware that logistics strategy is a key component of their overall strategy, and has to ensure the achievement of corporate objectives. According to the survey results provided by Straube et al. (2008), more than $80 \%$ of respondents see logistics as one success factor for internationalisation, and logistics processes need to be performed in close interaction with other corporate functions. A number of factors creating further complexity do exist. First, business objectives (e.g. in terms of commitment to growth and market penetration) and factors that impact on logistics performance (e.g. infrastructures and logistics market) vary over time and are country-related. Second, the logistics strategy is composed of different variables involving both tactical (e.g. inventory management) and strategic decisions (e.g. network design) that are critical to set up and have interdependencies (e.g. Schmidt and Wilhelm, 2000). In summary, setting the most suitable logistics strategy that is in line with corporate objectives for each export area over time is crucial and represent a challenge for logistics directors worldwide.

Despite the significance and the topicality of the problem, the internationalisation process from a logistics perspective has not been fully investigated so far in the literature. Specifically, the international logistics strategies have been examined by studying individual aspects separately, such as logistics strategies for entering new markets (e.g. Straube et al., 2008) and supply chain planning centralisation for multinational companies (e.g. Jonsson et al., 2013; Melacini et al., 2011). Additionally, previous contributions considered the company international logistics strategies from a static perspective, without investigating its evolution over time. Moreover, the generalizability of their results seems quite restricted, as they often focused the analysis on few companies (e.g. Jonsson et al., 2013; Simchi-Levi et al., 2009).

Our research intends to overcome the identified gap. Specifically, the study aims at shedding light on how companies align over time their international logistics strategy (i.e. in terms of single variables involved) with the internationalisation choices. This research offers a valuable contribution from both the academic and industry perspectives. From the academic viewpoint, it help overcome the approach adopted in extant contributions where individual logistics issues were studied separately, without providing a holistic perspective. From a practical viewpoint, a clear understanding of the main alternatives and variables to be set up may support managers to make informed decisions when designing their international logistics strategy. Specifically, modelling the relationship between international choices and logistics strategy allows managers to understand how: (i) to align such two components, and (ii) to redesign their logistics strategy over time based on their business evolution.

The remainder of the paper is organised as follows. The next section summarises the theoretical background. Afterwards, the research framework and 
questions are reported, and findings are discussed. Finally, conclusions and limitations are drawn.

\section{$2 \quad$ Literature review}

Coherently with the aim of this paper, the theoretical background is hereinafter discussed according to the two different issues involved, i.e. company internationalisation process and company international logistics strategy. The first subsection summarises the key contributions on the company internationalisation process, whereas the second reviews the extant literature on the main logistics variables affected by company internationalisation choices.

\subsection{Company internationalisation process}

According to the extant literature, the entry modes into foreign markets can be classified into two main types, i.e. equity or non-equity (e.g. Harzing, 2002). In the first case (equity), the company acquires an existing local company or makes a green-field investment and has to decide whether partially or wholly own the local enterprise (e.g. Hennart and Park, 1993). The plant or sales subsidiary opening belongs to this case. In the second case (non-equity), the company exports via agents and/or licensing (e.g. Caves, 1982).

The internationalisation process - and especially those factors that impact on this decision - has received a considerable attention by previous contributions, and different theories have been developed to explain the reasons behind company internationalisation, such as the internalisation theory (Buckley and Casson, 1976), the transaction cost theory (Hennart, 1982), and the eclectic paradigm (Dunning, 1980). Such theories are seen as 'economic'. Another, yet consolidated, stream of research has been characterised as 'behavioural'. According to this latter (i.e. behavioural), the internationalisation process evolution is based on a sequence of incremental decisions and a gradual market learning. The main contribution is represented by the Uppsala model. Proposed by Johanson and Vahle (1977), it is a behavioural and dynamic model that focuses on the development of the individual company, and particularly on its gradual acquisition, integration, and use of knowledge about foreign markets and operations, and on its successively increasing commitment to foreign markets. According to the Uppsala model and other contributions (e.g. Johanson and Wiedersheim-Paul, 1975), four progressive stages can be selected by a company to sell products in foreign markets over time: no regular export activities, export via independent agents, creation of sales subsidiary, and production establishments. All stages in the internationalisation process can be explained using the concepts of 'state' and 'change' aspects. The 'state' aspects refer to the foreign market knowledge and commitment. The 'change' aspects explain the 
transition among the stages of the internationalisation process, and consist in: (i) commitment decisions that can strengthen the position in the foreign market and (ii) learning process from the experience of the current business activities. The 'change' and 'state' aspects affect each other, so that a stronger position in the market and better performance lead to a higher level of commitment and market knowledge.

A number of empirical studies have supported the Uppsala model and have indicated that the internationalisation process as explained by this model has a positive impact on performance (e.g. Barkema et al., 1996; Bello and Barksdale, 1986; Luo and Peng, 1999; Sezen, 2008). Additionally, the Uppsala model has been progressively adjusted to explain specific internationalisation processes (e.g. Camuffo et al., 2007), and further revised (Johanson and Vahle, 2009). The revised model maintains its original basic structure, especially in terms of 'state' and 'change' aspects and their mutual relationship, but considers the fact that the internationalisation process is pursued within a network of companies (e.g. local partners).

\subsection{Company international logistics strategy}

As Rushton et al. (2014) note, besides the increasing importance of distribution, logistics and supply chain, a growth in the number of associated definitions has been progressively registered. As such, the expression 'international logistics strategy' may refer to different meanings in the literature. For instance, the early literature on global supply chains in the '90s, introduced such expression when referring to decisions related to facility location, network design, production/distribution centralisation, postponement strategies along the supply chain (e.g. Cooper, 1993; Schmidt and Wilhelm, 2000). Other authors have referred to 'international logistics strategy' as the logistics strategy supporting company international sales of finished products (e.g. Creazza et al., 2010; Straube et al., 2008; Rushton et al., 2014). This latter connotation is coherent with the aim of the present paper, and has been hereinafter adopted.

Although the topic of company international logistics strategy has been widely tackled in the literature, a structured and hierarchical description of its building variables has not been in-depth developed so far. As an example, Straube et al. (2008) considered the 'logistics planning' as one of the steps of the company internationalisation process that includes the definition of service levels, intended lead times, inventory policy, network structure, capacity calculation, allocation of facilities (e.g. warehouses), IT integration, decisions about logistics outsourcing, and preparation of tenders. According to Rushton et al. (2014), it is possible to identify a list of key areas representing the major components of distribution and logistics valid for most companies, namely: transport (e.g. mode of transport and load planning), warehousing (e.g. number 
and size of distribution depots), inventory (e.g. stock level), packaging (e.g. type of unit load) and information (e.g. forecasting). In summary, a number of contributions do exist but they are focused on individual aspects of the logistics strategy (e.g. Jonsson et al., 2013; Melacini et al., 2011), without offering a holistic view.

For the purpose of this study, we reviewed the literature in order to identify the main logistics decisions that may be affected by the company internationalisation choices. The logistics variables found can be summarised as follows: (i) logistics network design, (ii) inventory planning centralisation level, (iii) transport planning, and (iv) level of control on logistics flows. The review of the contributions for each variables is reported below. The proposed order attempts to reproduce the mechanism of a typical decision-making process for setting the international logistics strategy in the case the distribution channel and the service level have been already defined. First, the company selects the trade terms with the buyer. Once the logistics problem is fully defined, the company starts to design the logistics network in order to send the goods from the warehouse of finished products to the destination points in the export areas. In this process, the role to be assigned to logistics service providers has been taken into account. After this strategic decision, the company addresses more 'tactical' decisions, i.e. related to inventory and transport planning.

Incoterms (International Commercial Terms) represent the key indicators for the level of control on logistics flows. They contribute to describe the company international logistics strategy, as they affect the trade cost in global supply chains (Blanco and Ponce Cueto, 2015). According to Blanco and Ponce Cueto (2015), the trade term depend on the relationship between the seller and the local actor (i.e. buyer). A strategic advantage can be gained by a company willing to facilitate the sale of its products by assisting the importer in the shipment (David and Stewart, 2010). The company positioning on the market in terms of internationalisation choices, sales volume regularity and entity is also a key aspect. Small and beginning exporters often prefer that the buyer organises transport (Malfliet, 2011).

Among the key variables defining the international logistics strategy, the literature (e.g. Abrahamsson et al., 2003; Straube et al., 2008; Tracey et al., 2005) consistently refers to the type of relationship with logistics service providers (LSP). Besides, the role and impact of LSP can be different based on the internationalisation choice (e.g. Straube et al., 2008). When a company operates in different markets all over the world, it is crucial to identify properly the suitable relationship to be established with the local suppliers, especially when they provide strategic services such as logistics activities (Li et al., 2012). This is significant especially in the early stage of the internationalisation process 
when LSP can have a direct impact (i.e. positive or negative) on the company successful entry into the new market (Sandberg and Abrahamsson, 2011).

The logistics network design is a strategic decision involved when shaping the company international logistics strategy, and has a significant impact on the process performance (e.g. Pero et al., 2010; Sezen, 2008). The design of global logistics networks refers to the number, location and capacities of warehouses, and material flow through the network (e.g. Chopra and Meindl, 2004; Creazza et al., 2010). The logistics network design has been addressed by numerous studies, mainly using either mathematical models, heuristic techniques, or simulation models (Chopra and Meindl, 2013; Creazza et al., 2010; Meixell and Gargeya, 2005). In their review, Meixell and Gargeya (2005) offer a complete overview and classification of the models proposed in the literature.

Another key issue when defining the international logistics strategy consists in the inventory planning centralisation level (e.g. Melacini et al., 2011). Although planning is more critical to handle in case of inter-organisational supply chains, it represents an important challenge also in internal supply chains (Forget et al., 2008). Specifically, demand forecasting and inventory planning are particularly demanding for companies selling their products in different foreign markets (Pirttila and Niemi, 1996; Rudberg and West, 2008). In this case, a high inventory planning centralisation level implies that all decisions are made by the headquarter. Conversely, a low centralisation level implies that the subsidiaries are quite autonomous. Between these two cases, another intermediate approach may be identified that implies a certain level of coordination (e.g. Pirttila and Niemi, 1996; Rudberg and West, 2008). Previous contributions (e.g. Melacini et al., 2011) also showed a strong correlation between the levels of internationalisation and planning process centralisation: the higher the internationalisation of production and procurement processes, the stronger the need for centralising the planning due to the increase in logistics complexity.

Also the transport planning is a vital part of the international logistics strategy, and it is strictly connected with the company internationalisation choices. Transport is a key process in the distribution as it acts as a physical link between customers and suppliers (e.g. Mason et al., 2007). Different transport planning approaches can be defined depending on how the order delivery to the export areas is managed. Referring to the literature, the existing approaches are not fully described. Only individual issues have been studied separately in some papers, such as the transport mode. For example, Zeng (2003) and Dallari et al. (2006) considered three global transport service categories: airfreight, less than container load (LCL) shipping, and full container load (FCL) shipping. A more recent study by Creazza et al. (2010) evaluated different international logistics strategies mainly in terms of logistics network configuration and transport mode. 


\section{$3 \quad$ Research framework and questions}

The literature review shows that both company internationalisation process and related motivations have been widely studied (e.g. Buckley and Casson, 1976; Dunning, 1980; Hennart, 1982). The stages along which a company may increase its international expansion can be considered well-defined, as well as the description of the dynamics in moving along the stages. At this regard, the Uppsala model (Johanson and Vahlne, 1977) seems to be the most consolidated contribution. From this viewpoint, the main aspects explaining the evolution of the internationalisation process are the company commitment and continuous learning process.

Typically, the structure of the company internationalisation process implies, first, making strategic decisions about the enter in a new market or the change its position in a foreign market already entered; then, a top-down process start from the top-level decisions at the beginning to middle and lower management level decisions finalised to meet the corporate objectives. In other words, the company internationalisation choices affect the decisions at any other level and business functions as they should be aligned sequentially with the strategic goals. According to Straube et al. (2008), for instance, the process of entering into a new market consists of four sequential steps: evaluation of the new market, strategic planning, and then logistics planning and implementation of the logistics system. Moreover, literature review showed that the single variable of the international logistics strategy potentially are affected by the internationalisation choices (e.g. David and Stewart, 2010; Melacini et al., 2011; Rushton et al., 2014).

However, literature review shows that there is no clear understanding of the variables involved, their operationalisation, and how they can be set coherently with each other and over time according to the internationalisation choices. In Straube et al. (2008), almost $70 \%$ of the respondents in the survey call for more management recognition and support to avoid suboptimal international logistics networks. How the foreign market and the company success evolve in the future is unpredictable. Considering also that this problem is different in each export area, the design and management of international logistics strategies are challenging for companies.

This premise opens up the need for further research on how companies change their international logistics strategy over time by modifying their logistics variables based on the company internationalisation process. This research aims at providing empirical-based evidence on the development and implementation of international logistics strategies to better explain both interaction and behaviour of the key logistics variables involved. Additionally, 
the research objectives include the investigation on how the international logistics strategy may be shaped in relation with the company internationalisation choices, exploring its building variables. At the current stage of the research, the scope of the analysis focuses on the distribution process of finished goods managed according to a make-to-stock (MTS) approach and it does not include the study of the internationalisation process of small companies and multinational companies that have a production establishments in the foreign market. Indeed, for instance, the decisions on plant location are also related to other factors different from the evolution of the international sales process, such as the search for lower-cost manufacturing locations or the proximity to raw material suppliers.

In order to address the above-mentioned aims, a framework was drawn starting from the literature review (Figure 1). In particular, we defined three levels for the internationalisation process evolution, namely: (i) early stage, i.e. export via independent agents or distributors, (ii) intermediate stage, i.e. export via sales subsidiary, and (iii) advanced stage, i.e. export via company own stores. As far as the company international logistics strategy is concerned, the following variables have been considered: (i) level of control on logistics flows, (ii) type of relationship with LSP, (iii) logistics network design, (iv) inventory planning centralisation level, and (v) transport planning.

Within this research framework, the following research questions have been investigated:

RQ1: What are the key logistics variables affected by the company internationalisation choices?

RQ2: What are the main company international logistics strategies based on the interaction and behaviour of the key variables identified?

RQ3: How do company internationalisation choices affect the international logistics strategy?

Figure 1. Research framework 


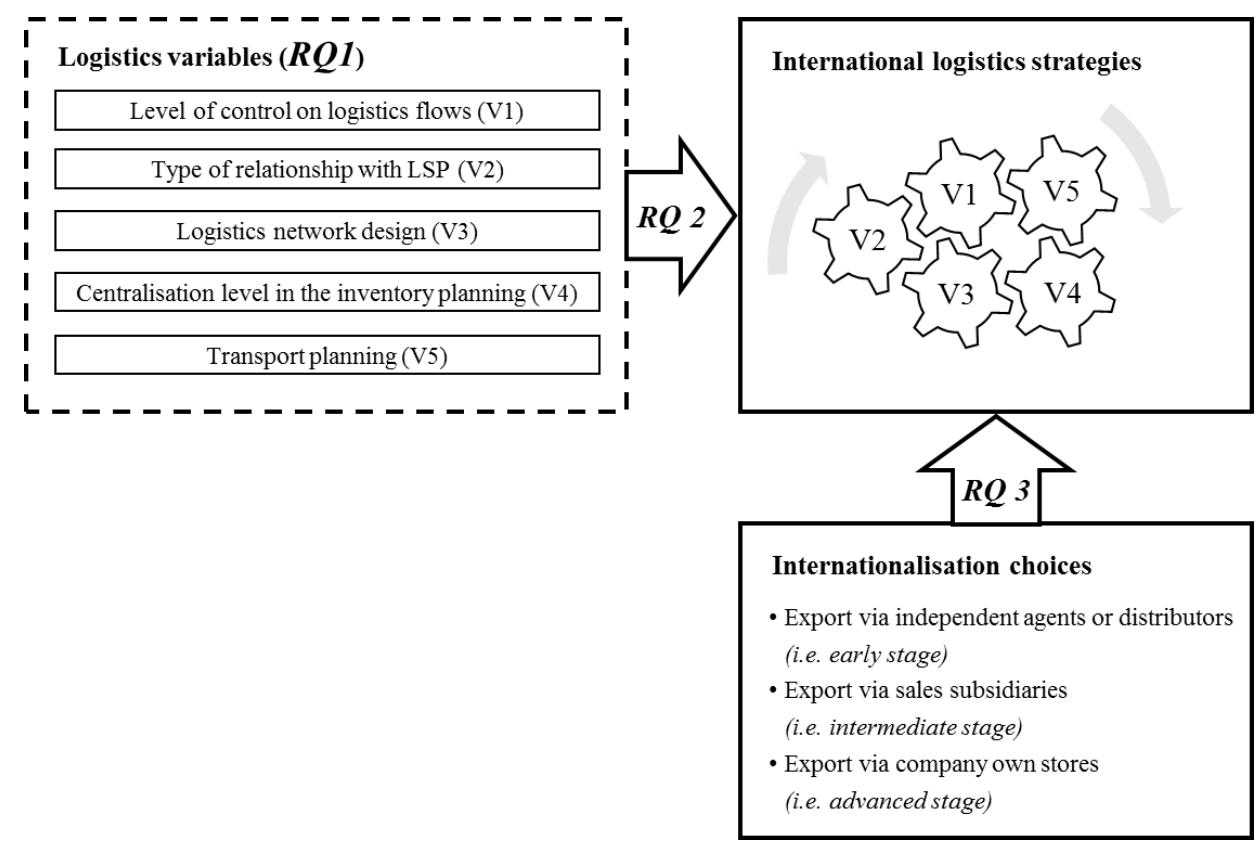

\section{$4 \quad$ Research method}

The research methodology consists of three main stages, i.e. literature review, development of the research framework and empirical application of the designed framework to the research sample. The theoretical analysis mainly contributed to provide the necessary grounds for the research framework definition. The empirical investigation consisted in a series of case studies involving companies operating in various business sectors (as per Table 1), exporting their finished goods in different foreign countries. The case study approach was selected as the most suitable methodology as it is recognised to be the most appropriate means to investigate relationships among variables and address explorative or explanatory questions regarding a set of facts (Choi and Wacker, 2011; Eisenhardt, 1989; Ketchen et al., 2011; Yin, 2013). In our case, the research questions focus on how companies design their international logistics strategies, also in light of their internationalisation choices. It should be noted that each company may have different export areas and, in general, different logistics strategies and distribution channels for each. For these reasons the company single export area has been selected as unit of analysis, and the embedded multiple case study approach has been adopted. Additionally, while performing the case studies, we introduced a retrospective perspective to capture 
the evolution of the international logistics strategy over time, from the company entry in the export area to present, throughout the internationalisation stages that companies have experienced (i.e. $R Q 3$ ).

To enable an adequate analysis, in line with the research scope and questions, companies included in the sample are big national or multinational companies that have plants concentrated in Europe and export their finished goods in countries belonging to other continents with a MTS production system.

The selected cases vary across business sectors (e.g. health and care, sanitary technology, and food) in order to consider a heterogeneous sample, thus allowing to explore the research questions in different environmental and market conditions. The selected cases also vary in terms of product value density measured as product price to weight ratio - that represents a key variable for logistics (e.g. Chopra, 2003; Cooper, 1993). An overview of the features of the six companies included in the sample is provided in Table 1. A total number of 14 export areas have been taken into account.

Table 1. Summary of the characteristics of the six examined companies

\begin{tabular}{|c|c|c|c|c|}
\hline Company & Business sector & $\begin{array}{l}\text { Annual group } \\
\text { sales }\end{array}$ & $\begin{array}{l}\text { Product price to } \\
\text { weight ratio }\end{array}$ & $\begin{array}{l}\text { Unit of analysis (i.e. } \\
\text { export area) }\end{array}$ \\
\hline A & $\begin{array}{l}\text { Baby, health \& } \\
\text { beauty care }\end{array}$ & 1.5 billion $€$ & Medium & $\begin{array}{l}\text { A1: South America } \\
\text { A2: Asia-Pacific area } \\
\text { A3: } \text { CIS }^{(*)}\end{array}$ \\
\hline $\mathrm{B}$ & Porcelain stoneware & 0.5 billion $€$ & Low-medium & $\begin{array}{l}\text { B1: North America } \\
\text { B2: Middle East }\end{array}$ \\
\hline $\mathrm{C}$ & Medical technology & 1.1 billion $€$ & Medium & $\begin{array}{l}\text { C1: Asia-Pacific area } \\
\text { C2: } \text { CIS }^{(*)}\end{array}$ \\
\hline $\mathrm{D}$ & Sanitary technology & 1.8 billion $€$ & Low-medium & $\begin{array}{l}\text { D1: Pacific area } \\
\text { D2: South America }\end{array}$ \\
\hline $\mathrm{E}$ & $\begin{array}{l}\text { Electrical and } \\
\text { machinery industry }\end{array}$ & 0.1 billion $€$ & Medium-high & $\begin{array}{l}\text { E1: Middle East } \\
\text { E2: North America } \\
\text { E3: South America }\end{array}$ \\
\hline $\mathrm{F}$ & Food industry & 2.5 billion $€$ & Low & $\begin{array}{l}\text { F1: Middle East } \\
\text { F2: North America }\end{array}$ \\
\hline
\end{tabular}

(*) CIS $=$ Commonwealth of Independent States (e.g. Russian, Kazakhstan, Moldova, Azerbaijan)

Case studies were performed by means of in-depth interviews with Logistics and Supply Chain Directors using a semi-structured questionnaire, ensuring interviewers' control, instant feedback and clarification of specific issues. General information about the company and their operating context were also collected using secondary sources (i.e. annual reports, company website, and articles published in trade journals), with the purpose of triangulating the interviews with further data source and reducing biases of respondents. A case 
study protocol was developed prior to data collection to ensure consistency among the procedures followed among cases. According to Yin, 2013, the document contained information such as case study questions, data collection guidelines, data sources, and the criteria for interpreting the findings. The semistructure questionnaire was prepared according to the research framework. It was composed of 3 main sections, i.e. (i) general information related to the company and their export areas, (ii) company internationalisation choices in each export area, and (iii) company international logistics strategy.

In order to analyse the data, we first transcribed the recordings of all interviews when information was still fresh in the mind of researchers; after that, we performed both a within-case analysis and then a cross-case comparison. With reference to $R Q 1$, the significance of each variable was assessed by two independent researchers along a 3-point scale (i.e. 'low', 'medium', and 'high'). As far as the variable operationalisation is concerned, it was updated after each interviews, continuously comparing the information collected through the different cases and reformulating the variable dimensions whenever more meaningful categories were found. Pattern matching was useful for identifying the company international logistics strategies $(R Q 2)$. Finally, the transcribed interviews were analysed using explanation-building techniques in order to investigate the potential impact of the company internationalisation choices on the international logistics strategy $(R Q 3)$.

\section{$5 \quad$ Discussion and findings}

This section discusses the results emerged from the case study analysis according to each research question. The discussion of the information collected during the case studies in comparison with insights emerged from the literature review is also provided.

\subsection{Variables defining the company international logistics strategy}

This section compares the variables coming from the research framework with those found in the case study analysis $(R Q 1)$. Table 2 reports the significance of each variable achieved from the case studies. As shown in the table, almost all the identified variables are considered as significant for the export areas examined. The only exception is the type of relationship with LSP: although found in literature as an element defining the international logistics strategy and being affected by the internationalisation choices, for the majority of the export areas examined it has a low significance, whereas for only 6 cases the significance was assessed as medium.

All companies recognise that the strategic collaboration with LSP is a key component of a logistics approach in the context of a foreign market, but they 
do not consider it as related to internationalisation choices. For example, in the case of A2, company A stated, 'we developed a strategic relationship with the provider to entry in the Asia-Pacific area, but the evolution of the collaboration was not strictly related to the internationalisation strategy'. For D1, company D had a similar comment: 'We started a strategic relationship with a logistics service provider to entry in the Asia region and then we have carried on this relationship from that moment, even if our distribution model changed then'.

Table 2. Significance of each logistics variable based on the case study analysis

\begin{tabular}{llllll}
\hline Case & $\begin{array}{l}\text { Level of control } \\
\text { on logistics } \\
\text { flows }\end{array}$ & $\begin{array}{l}\text { Logistics } \\
\text { network } \\
\text { design }\end{array}$ & $\begin{array}{l}\text { Inventory } \\
\text { planning } \\
\text { centralisation } \\
\text { level }\end{array}$ & $\begin{array}{l}\text { Transport } \\
\text { planning }\end{array}$ & $\begin{array}{l}\text { Type of } \\
\text { relationship } \\
\text { with LSP }\end{array}$ \\
\hline A1 & High & High & High & High & Low \\
A2 & High & High & High & High & Medium \\
A3 & High & High & High & High & Medium \\
B1 & High & High & High & High & Low \\
B2 & High & High & High & High & Low \\
C1 & High & High & High & High & Medium \\
C2 & High & High & High & High & Medium \\
D1 & High & High & High & High & Medium \\
D2 & High & High & High & High & Low \\
E1 & High & High & Low & Low & Low \\
E2 & High & High & Low & Low & Low \\
E3 & High & High & Low & Low & Low \\
F1 & High & High & Medium & Medium & Low \\
F2 & High & High & Medium & Medium & Medium \\
\hline & & & &
\end{tabular}

Focusing on the variables considered as significant, Table 3 provides an overview of the operationalisation of each variable, thus summarising the case study analysis based on the current situation at the moment of the interviews, without losing in completeness when describing the operationalisation.

Table 3. Summary of the logistics variables based on the case study analysis

\begin{tabular}{lllll}
\hline Case & Level of control on & Logistics & Inventory & Transport planning \\
\hline
\end{tabular}




\begin{tabular}{|c|c|c|c|c|}
\hline & logistics flows & $\begin{array}{l}\text { network } \\
\text { design }\end{array}$ & $\begin{array}{l}\text { planning } \\
\text { centralisation } \\
\text { level }\end{array}$ & \\
\hline $\mathrm{A} 1$ & High & $\begin{array}{l}\text { 2-echelon } \\
\text { network }\end{array}$ & Centralised & $\begin{array}{l}\text { Managed for all areas } \\
\text { jointly }\end{array}$ \\
\hline $\mathrm{A} 2$ & Low & $\begin{array}{l}\text { 1-echelon } \\
\text { network }\end{array}$ & Decentralised & $\begin{array}{l}\text { Managed for each } \\
\text { single area separately }\end{array}$ \\
\hline A3 & Low & $\begin{array}{l}\text { 1-echelon } \\
\text { network }\end{array}$ & Decentralised & $\begin{array}{l}\text { Managed for each } \\
\text { single area separately }\end{array}$ \\
\hline B1 & Low & $\begin{array}{l}\text { 1-echelon } \\
\text { network }\end{array}$ & Decentralised & $\begin{array}{l}\text { Managed for each } \\
\text { single area separately }\end{array}$ \\
\hline B2 & Low & Not significant & Coordinated & Not significant \\
\hline $\mathrm{C} 1$ & Low & $\begin{array}{l}\text { 1-echelon } \\
\text { network }\end{array}$ & Coordinated & $\begin{array}{l}\text { Managed for each } \\
\text { single area separately }\end{array}$ \\
\hline $\mathrm{C} 2$ & Low & Not significant & Coordinated & Not significant \\
\hline D1 & Low & Not significant & Coordinated & Not significant \\
\hline D2 & Low & Not significant & Decentralised & Not significant \\
\hline E1 & Low & Not significant & Coordinated & Not significant \\
\hline $\mathrm{E} 2$ & Medium & Not significant & Coordinated & Not significant \\
\hline E3 & Medium & Not significant & Coordinated & Not significant \\
\hline $\mathrm{F} 1$ & Low & Not significant & Coordinated & Not significant \\
\hline $\mathrm{F} 2$ & Low & $\begin{array}{l}\text { 1-echelon } \\
\text { network }\end{array}$ & Decentralised & $\begin{array}{l}\text { Managed for each } \\
\text { single area separately }\end{array}$ \\
\hline
\end{tabular}

The information collected for each variable through the case studies is hereinafter summarised and discussed.

Level of control on logistics flows. As above-mentioned in the methodology section, the level of control on logistics flows was investigated through the Incoterm type adopted and operationalised by defining a 3-point scale (i.e. 'low', 'medium', and 'high'). Although quite disregarded by the extant literature on the logistics process on a global scale, the majority of the cases confirms the significance of this variable (Table 3 ). Table 4 shows that the majority of the cases applies a low level of control on logistics flows (i.e. use of Incoterms E and F). According to the literature, Incoterms $\mathrm{E}$ and $\mathrm{F}$ are the most adopted by beginning exporters. As an example, for $\mathrm{D} 2$, company $\mathrm{D}$ stated: 'we just sell to our local agents at ex-works prices'. For $\mathrm{C} 1$, company $\mathrm{C}$ asserted: 'we just sell to distributors and we are not interested in managing transport and logistics processes'. Differently from company C, for E3, company E sells via distributors but applies a medium level of control on logistics flow: 'we prefer to have in charge the transport up to the distribution centres of the local distributors as we are able to perform full container load shipping'). Another example of high control on logistics flows is the case of A1, for which company 
A affirmed: 'we are engaged in the shipments from our Italian central warehouse till the local warehouse that deliveries to our own stores'.

In summary, selecting the Incoterms to be used affect the company level of control on their logistics process to the export areas.

Logistics network design. Table 3 confirms that the logistics network design is a significant variable. According to the information collected through the case studies, decisions related to logistics network design mainly imply the selection among direct shipment, 1-echelon networks and 2-echelon networks. As for the B2 or E1 cases, direct shipments are performed by companies that sell products without having local distribution centres. In the case of E1, for instance, 'the products are sold through local agents and the annual total flow to be shipped is low (the delivery frequency is one shipment per month on average)'. On the contrary, having a local warehouse (i.e. 1-echelon network) may be necessary due to customer service level requirements (e.g. C1 and F2 cases). In the case of $\mathrm{C} 1$, for example, company $\mathrm{C}$ stated: 'we opened a local warehouse to be closer to the customers as they ask for very short delivery lead times'. In such cases, the products are shipped from the European plants to distribution centres located in each export area. The reasons behind the adoption of a 2-echelon network lies in the presence of different countries with many delivery points within the same export area. This last situation was observed only for the A1 case, for which company A asserted that 'first [A] delivered its product only in Brazil and then it also expanded its market to the nearest countries; over time, due to the increase in logistics flows and service level offered, [A] has progressively opened new local warehouses in the South America region, supplied be the Brazilian warehouse'.

Inventory planning centralisation level. In line with the extant literature, the planning centralisation level has been confirmed to be a key aspect to be managed when defining the logistics strategy for the distribution on a global scale (Table 3). The following aspects are those mainly involved in such process with reference to each export area: sale forecasts, inventory management, and service level to the customers.

Inventory planning can be decentralised, i.e. only some decisions made by the subsidiaries are shared with the headquarter. For the B1 case, for instance, company B stated: 'the subsidiaries work in completely autonomy in managing inventories, even if they have to meet the company targets in terms of maximum stock levels'. A similar situation was observed in the case of F2, for which company $\mathrm{F}$ asserted that "the local subsidiaries have to be coordinated with the headquarter with reference to the maximum level of stock for some product categories and the warehousing performance of the logistics service provider'. In some cases, the headquarter does not have the full visibility on the 
information needed to make decisions. For the D2 case, for example, company D asserted: 'at the moment we don't have an IT interface that enable information sharing between headquarter and subsidiaries - these latter are therefore fully independent'. The opposite situation happens in case of centralised planning, i.e. the subsidiaries are not autonomous. This situation was observed only in the A1 case, for which company A stated that 'the subsidiaries are engaged only in the sale forecast due to the proximity to the market; then, the headquarter manages inventories at the local central warehouse and replenishments to the subsidiaries. This behaviour, together with the choice of managing the transport process up to the local warehouse, allows the company to exploit synergies coming from the jointly management of the logistics flows of all subsidiaries located in different countries of the South America area'. However, the planning is coordinated between the headquarter and the subsidiaries in the majority of the cases, i.e. the company develops the sale forecasts together with the independent agents but is not involved in managing the logistics process (e.g. in the $\mathrm{C} 1$ and $\mathrm{C} 2$ cases). For instance, company $\mathrm{F}$ revealed for F1, in these situations 'there is a key account with commercial and marketing competences, dedicated to the relationship with the export area'.

From the company perspective, choices on inventory planning centralisation level imply different opportunities of controlling the inventory level. For instance, centralising allows companies to have visibility up to the local warehouses, thus allowing to directly manage the overall inventory level in the network.

Transport planning. In line with the literature, the transport planning is a variable of the international logistics strategy, and company decisions from this viewpoint are made according to the company internationalisation choices (Table 3). According to Table 4, the control on transport planning can be 'not significant' as the transport problem is quite simple to manage. As for the D2 case for instance, company D stated: 'the company engages only the transport to the borders of the export country and the frequency of deliveries is low'. As a consequence, the level of competences required for the transport planning is low as found in some cases (e.g. E2 and E3). Instead, as in the C1 case, when a company exports via sales subsidiaries and its logistics network consists in a local warehouse that delivers goods to the subsidiaries, the transport planning is more complex: '[C] manages the delivery of goods to the warehouse for each export area; sales volumes are not high and transports are supplied by freight forwarders through less than container load shipping services'. Finally, the transport planning can be managed jointly for all the export areas. This situation was observed only in the A1 case. As stated by the Logistics Director of company A for the A1 case: 'when the number of export areas and the amount of logistics flows increased, the company started to optimise transport activities by 
managing jointly the flows for different markets, for instance by full container load service or by sea instead of air freight'.

For companies, managing the transport planning jointly for all the export areas allows to obtain economies of scale, and therefore, to reduce the overall costs.

In summary, from the case studies analysis it can be inferred that the following four variables are those better describing a company international logistics strategy and are affected by the evolution of the internationalisation process: (i) level of control on logistics flows, (ii) distribution network design, (iii) inventory planning centralisation level, and (iv) transport planning. Instead, the type of relationship with LSP does not seem to be related to the internationalisation choices based on the results obtained from the companies of the sample.

\subsection{Company international logistics strategies}

To identify the main international logistics strategies adopted by companies (RQ2), the case study analysis was used to find a common pattern in the correlation among the variables (RQ2). Results allow identifying three international logistics strategies that we named: (i) International sale, (ii) International outpost, and (iii) International network. Table 4 summarises the features of each strategy by reporting the alternatives for each of the four variables.

Table 4. International logistics strategies emerged from the case studies

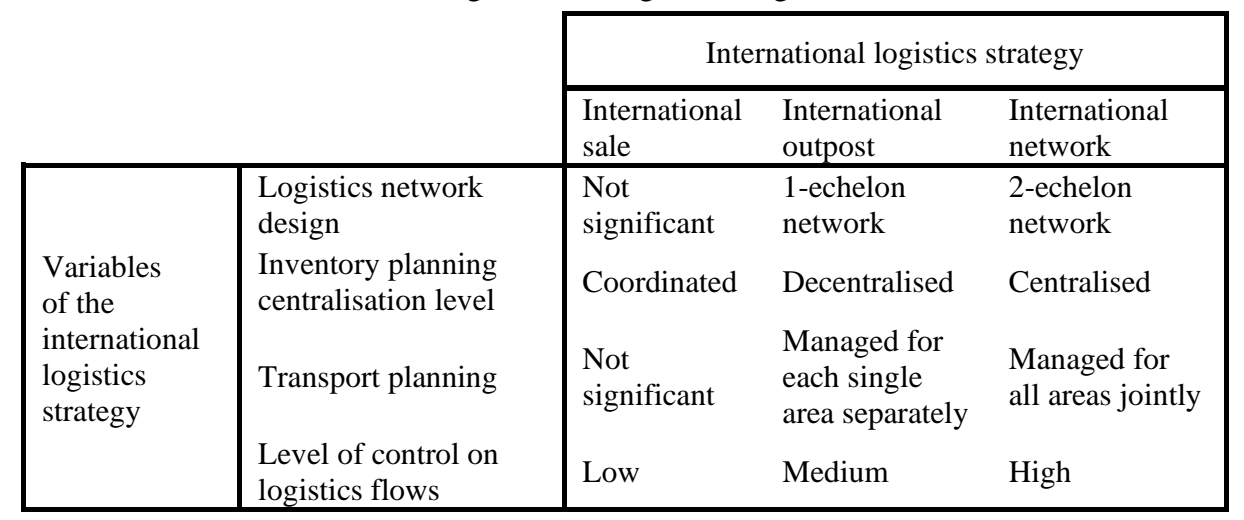

The International sale logistics strategy is adopted by companies that focus on the sales channel of distribution rather than on logistics. Indeed, such companies sell their products in foreign market following an irregular series over time. Adopting this strategy implies that companies do not configure their logistics strategy to directly control their flows, neither to be as close as possible 
to the market. As direct shipments are typically performed, distribution network configuration and transport planning are not perceived as significant challenges. A coordinated distribution planning has been found in this case. This means that the local players (e.g. independent agents) have a certain level of autonomy when planning the distribution, and that the company just coordinates with the local players. On the one hand, companies adopting this strategy lose the possibility to manage and optimise their logistics process. On the other hand, they do not have the need for country-specific investments for each foreign market (e.g. local warehouses), neither strong capabilities for managing international freight transport.

Companies adopting the International outpost logistics strategy develop a stronger commercial relationship with the export area. A distribution network and a logistics process supporting such relationship is required. In this case, although companies are more interested in controlling the logistics flows and managing the transport planning, each relationship with the single export area is viewed independently from the others. However, due to the high knowledge of the market and the proximity to customers, the local actors maintain a certain level of control on the logistics and transport processes and are engaged in the distribution planning. Therefore, activities such as sale forecasts and inventory management are decentralised to the local actors. Companies adopting this strategy prefer to let the local areas more autonomous and flexible. From the company perspective, this requires to develop capabilities in each export area (e.g. competences to perform forecasting and inventory planning).

Finally, according to the International network logistics strategy, companies develop their logistics considering all the export areas jointly, differently from the International outpost strategy. The level of complexity - in terms of both distribution network structure and transport planning - is relatively high. The distribution planning is centralised as the headquarter develops the sales forecast and owns the entire decision-making process related to inventory management. Compared to the two previous options, such strategy mainly implies to manage different logistics flows among the export areas and to have stronger logistics capabilities.

The following section provides more details and examples related to the three above-described international logistics strategies, as well as findings on $R Q 3$.

\subsection{Impact of company internationalisation choices on the international logistics strategy}

To answer $R Q 3$ (i.e. how the company internationalisation choices affect the international logistics strategy), the international logistics strategies adopted over time in each export area in the sample have been summarised considering also the corresponding stages of the internationalisation process (Table 5). Results 
reveal that the company international logistics strategy is significantly influenced by company internationalisation choices. As shown in the table, the adoption of each strategy is concentrated in a specific internationalisation process stage. Specifically, the International sale strategy is more likely to be selected by companies in the early stage of their internationalisation process, the International outpost by companies in the intermediate stage, whereas the International network by companies in the advanced stage. Additionally, for a given export area the evolution of the international logistics strategy incrementally evolves together with the internationalisation process, thus confirming that the alignment between the commercial and logistics channels is crucial for companies.

Table 5. Alignment between internationalisation choices and international logistics strategies

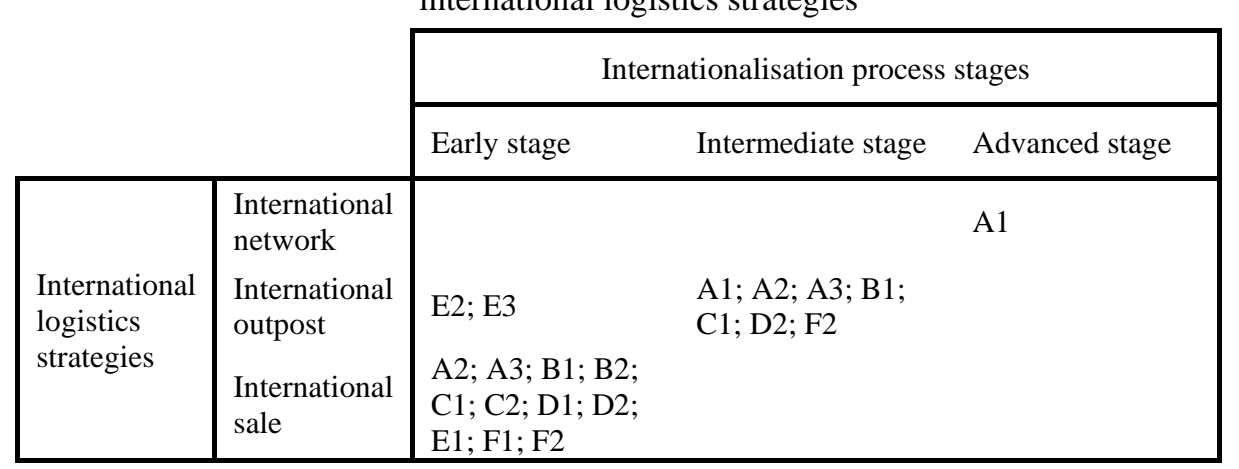

When a company operates in the early stage of the internationalisation process, its export volume is typically low, as well as its market knowledge. As a consequence, it operates in a foreign market with a low level of control on logistics and transport process (i.e. the International sale strategy is adopted). According to the case study analysis, at this stage, the choice of exporting via independent agents (as, for instance, in the B2, C2, D2, E1 cases) or distributors (as, for instance, in the A2, D1, E3, F1 cases) allows the company to not have own resources, and therefore sunk costs, that would have been present in case of own subsidiaries or store networks. Additionally, the benefits related to the absence of local warehouses and the possibility to overcome complexities (e.g. to face the local regulations and to collaborate with local logistics providers) have been cited by companies of the sample as other benefits from selecting the International sale strategy in the early stage of the internationalisation process. Such aspects have been highlighted especially for export areas such as Middle East and CIS countries (e.g. B2, C2, E1 and F1 cases). Such strategy for entering a new market has been adopted in all cases except for A1 case, in which the 
company opened a subsidiary when starting to sell its products in the new market.

E2 and E3 cases present an international logistics strategy that seems to be misaligned with the stage of the internationalisation process. The logistics strategy adopted is the International outpost as: (i) the company is engaged in the transport up to the distribution centres of the local distributors and (ii) the level of control on transport planning and logistics flows is medium. The main reason for this choice is related to the fact that the company operates on these exports areas from a number of years, and sales volumes have increased over time. As a result, the company is at a transition stage, since it aims at moving to the intermediate stage of the internationalisation process, and has already adopted a logistics strategy with some features of the International outpost.

Based on the empirical evidence, companies move from the early stage to the intermediate stage of the internationalisation process in order to control the distribution channel - thus having the possibility to directly manage the marketing of its products - and stay as close as possible to their final customers - so that potential market opportunities and threats can be rapidly understood. Looking at the sample, all companies - except for company E as above discussed - developed their logistics strategy from the International sale to the International outpost when they started to export via sales subsidiary (i.e. the intermediate stage of their internationalisation process). They report increase in sales and market experience as enabling factors to develop the second stage of the internationalisation process and the international logistics strategy. The transition to this second stage can also occur through the company acquisition of the local distributor (as in the A3 case). At this stage, companies let subsidiaries work autonomously in developing the sale forecasts, defining order quantities (i.e. decentralised planning), and also in managing transport and logistics process (i.e. adoption of Incoterms $\mathrm{E}$ or F). The local logistics network is composed of one distribution centre (i.e. 1-echelon network) that receives FCLs.

In the examined sample, no companies have already fully implemented the International network strategy. Only company A (A1 case) is evaluating the adoption of such approach in South America where the advanced stage of the internationalisation process has been reached - i.e. the company is selling its products via own stores. Company A intends to build a 2-echelon logistics network composed of a central distribution centre for the entire export area and other regional depots in each country belonging to the area. Through this project, company A intends to support the development of its business in this area with a more efficient close-to-the-market logistics network. Based on the information collected during the case studies, this approach seems to imply a more centralised planning and control on the transport process (i.e. adoption of Incoterms C and D). This seems to support the findings of the theoretical 
analysis, according to which the higher the company internationalisation, the stronger the need for centralising the planning due to the increase of logistics complexity.

It should be noted that a company has not necessarily to go through all the stages. For instance, a company can directly go to the intermediate stage by adopting the International outpost as logistics strategy, without exporting via independent agents or distributors before this settlement (as in the A1 case).

With reference to the factors driving the transition among the stages of the model, the case studies analysis supports the fact that a deep knowledge as well as sales volume increase over time are the key drivers that allow companies to develop their distribution channel in terms of both commercial and distribution channels. However, other driving factors have been found that can also explain the above-discussed situation for A1. In case A1, the main enabling aspects for the International network logistics strategy are: (i) homogeneity among the countries in terms of product types and logistics features, (ii) stress on the logistics process (e.g. high requirements on service levels and geographical dispersion of the delivery points), and also (iii) adoption of Information Technology (IT) systems. Moreover, the risk that the company intends to hold also explains the transition along the stages. For instance, the adoption of the International network strategy implies a higher risk compared to the International outpost strategy, for instance due to investment that cannot be exploited in another areas.

\section{Conclusions}

This paper explores the effect of the company internationalisation choices on its international logistics strategy by means of a multiple case study methodology. According to the research background and case study analysis, the key building variables of the company international logistics strategy that are related to the company internationalisation choices have been detected, thus answering $R Q 1$. Specifically, the following variables have been identified: (i) level of control on logistics flows, (ii) logistics network design, (iii) inventory planning centralisation level, and (iv) transport planning.

Based on the interaction and behaviour of the key variables, three international logistics strategies have been identified (as per $R Q 2$ ), namely: (i) International sale, (ii) International outpost, and (iii) International network. Results suggest that companies may progressively adopt these three international logistics strategies in sequence, following the evolution of their internationalisation process $(R Q 3)$. Specifically, the International sale strategy is more likely to be chosen by companies in the early stage, the International 
outpost by those in the intermediate stage, whereas the International network by those in the advanced stage.

This research offers both academic and practical implications. From the academic perspective, this study contributes to: (i) overcome the approach adopted in extant contributions where individual logistics issues were studied separately; (ii) understand the evolutionary process of the company international logistics strategy, and (iii) deepen the effects of the company internationalisation choices on its international logistics strategy. Hence, the present paper can be viewed as starting point for the development of a normative model supporting companies in aligning their international logistics strategy with their plans in terms of internationalisation. From a practical viewpoint, a clear understanding of the main alternatives and variables to be set up may support managers to make informed decisions when designing their international logistics strategy. Specifically, modelling the relationship between international choices and logistics strategy allows managers to understand how: (i) to align such two components, and (ii) to redesign their logistics strategy over time based on their business evolution.

Although this study offers interesting insights on the decision making process related to the company international logistics strategy, the conclusions drawn require further effort to be adequately generalised. Specifically, additional effort is recommended with the aim of further exploring the factors driving the evolution of the logistics strategy such as the country-, company- and productspecific elements (e.g. local market regulations, financial aspects and product innovation rate). 


\section{References}

Abrahamsson, M., Aldin, N. and Stahre, F. (2003) 'Logistics Platforms for Improved Strategic Flexibility', International Journal of Logistics Research and Applications: A Leading Journal of Supply Chain Management, Vol. 6, No. 3, pp. 85-106

Barkema, H. G., Bell, H. J. and Pennings, J. M. (1996) 'Foreign Entry, Cultural Barriers, and Learning', Strategic Management Journal, Vol. 17, No. 2, pp. 151-166

Bello, D.C. and Barksdale, H.C. (1986) 'Exporting at Industrial Trade Shows', Industrial Marketing Management, Vol. 15, No. 3, pp. 197-206

Blanco, E. E. and Ponce Cueto, E. M. (2015) Modeling the Cost of International Trade in Global Supply Chains, MIT Center for Transportation \& Logistics, Cambridge (MA)

Buckley, P. J. and Casson, M. (1976) The Future of the Multinational Enterprise, Holmes \& Meier, New York

Camuffo, A., Furlan, A., Romano, P. and Vinelli, A. (2007) 'Routes Towards Supplier and Production Network Internationalization', International Journal of Operations \& Production Management, Vol. 27, No. 4, pp. 371-387

Caves, R. (1982) Multinational Enterprise and Economic Analysis, Cambridge University Press, New York

Choi, T.Y. and Wacker, J.G. (2011) 'Theory building in the OM-SCM field: Pointing to the future by looking at the past', Journal of Supply Chain Management, Vol. 47, N. 2, pp. 8-11

Chopra, S. (2003) 'Designing the distribution network in a supply chain', Transportation Research Part E: Logistics and Transportation Review, Vol. 39, No. 2, pp. $123-140$

Chopra, S. and Meindl, P. (2004) Supply Chain Management: Strategy, Planning and Operations, Prentice Hall, Upper Saddle River

Chopra, S. and Meindl, P. (2013) Supply Chain Management: Strategy, Planning and Operations, Pearson Education

Cooper, J. C. (1993) 'Logistics Strategies for Global Businesses', International Journal of Physical Distribution \& Logistics Management, Vol. 23, No. 4, pp. 12 -23

Creazza, A., Dallari, F. and Melacini, M. (2010) 'Evaluating Logistics Network Configurations for a Global Supply Chain', Supply Chain Management: An International Journal, Vol. 15, No. 2, pp. 154-164

Dallari, F., Marchet, G. and Melacini, M. (2006), 'Transportation strategies in the global supply chain' in Proceedings of the 4th International Logistics and Supply Chain Congress, Izmir, Turkey, pp. 527-534

David, P.A. and Stewart, R.D. (2010) International Logistics: the Management of International Trade Operations, Cengage Learning

Dunning, J.H. (1980) 'Toward an Eclectic Theory of International Production: Some Empirical Tests', Journal of International Business Studies, Vol. 11, No. 1, pp. 9-31 
Eisenhardt, K. M. (1989) 'Building Theories from Case Study Research', Academy of Management Review, Vol. 14, No. 4, pp. 532-550

Forget, P., D'Amours, S. and Frayret, J.M. (2008) 'Multi-behavior Agent Model for Planning in Supply Chains: An Application to the Lumber Industry', Robotics and Computer-Integrated Manufacturing, Vol. 24, No. 5, pp. 664-679

Harzing, A. W. (2002) 'Acquisitions versus greenfield investments: International strategy and management of entry modes', Strategic management journal, Vol. 23, No. 3, pp. 211-227

Hennart, J-F. (1982) A Theory of Multinational Enterprise, University of Michigan Press, Ann Arbor

Hennart, J-F. and Park, Y-R. (1993) 'Greenfield vs. acquisition: the strategy of Japanese investors in the United States', Management Science, Vol. 39, No. 9, pp. 1054-1070

Johanson, J. and Vahlne, J.E. (1977) 'The Internationalisation Process of the Company A Model of Knowledge Development and Increasing Foreign Market Commitments', Journal of International Business Studies, Vol. 8, No. 1, pp. 305-22

Johanson, J. and Wiedersheim-Paul, F. (1975) 'The Internationalization of the Company: Four Swedish Cases', Journal of Management Studies, Vol. 12, No. 3, pp. 305-322

Jonsson, P., Rudberg, M. and Holmberg, S. (2013) 'Centralised Supply Chain Planning at IKEA', Supply Chain Management: An International Journal, Vol. 18, No. 3, pp. 337-350

Ketchen, D.J., Tomas, G. and Hult, M. (2011) 'Building theory about supply chain management - some tools from the organizational sciences', Journal of Supply Chain Management, Vol. 47, No. 2, pp. 2-18

Li, J., Li, Y. and Shapiro, D. (2012) 'Knowledge Seeking and Outward FDI of Emerging Market Firms: The Moderating Effect of Inward FDI', Global Strategy Journal, Vol. 2, No. 4, pp. 277-295

Luo, Y. and Peng, M. (1999) 'Learning to Compete in a Transition Economy: Experience, Environment and Performance', Journal of International Business Studies, Vol. 30, No. 2, pp. 269-295

Malfliet, J. (2011) Incoterms 2010 and the mode of transport: how to choose the right term, Universiteit Ghent

Mason, R., Lalwani, C. and Boughton, R. (2007) 'Combining vertical and horizontal collaboration for transport optimisation', Supply Chain Management: An International Journal, Vol. 12, No. 3, pp. 187-199

Meixell, M.J., and Gargeya, V.B. (2005) 'Global supply chain design: A literature review and critique', Transportation Research Part E: Logistics and Transportation Review, Vol. 41, No. 6, pp. 531-550.

Melacini, M., Creazza, A. and Perotti, S. (2011) 'Analysis of Supply Chain Planning Centralisation for Multinational Companies', International Journal of Logistics Systems Management, Vol. 9, No. 4, pp. 478-500

Monczka, M. and Trent, J. (2006) 'Achieving Excellence in Global Sourcing', Sloan Management Review, Vol. 47 No. 1, pp. 24-32 
Pero, M., Rossi, T., Noé, C. and Sianesi, A. (2010) 'An Exploratory Study of the Relation Between Supply Chain Topological Features and Supply Chain Performance', International Journal of Production Economics, Vol. 123, No. 2, pp. 266-278

Peterson, K.J., Frayer, D.J. and Scannel, T.V. (2000) 'An Empirical Investigation of Global Sourcing Strategy Effectiveness', Journal of Supply Chain Management, Vol. 36, No. 2, pp. 29-38

Pirttila, T. and Niemi, P. (1996) 'Generic Organizational Choices for Logistics in Decentralized Organizations: Implications for inventory management', International Journal of Production Economics, Vol. 45, No. 3, pp. 195-202

Rudberg, M. and West, B.M. (2008) 'Global Operations Strategy: Coordinating Manufacturing Networks', Omega, Vol. 36, No. 1, pp. 91-106

Rushton, A., Croucher, P. and Baker, P. (2014) The handbook of logistics and distribution management: Understanding the supply chain, Kogan Page Publishers

Sandberg, E. and Abrahamsson, M. (2011) 'Logistics Capabilities for Sustainable Competitive Advantage', International Journal of Logistics: research and applications, Vol. 14, No. 1, pp. 61-75

Schmidt, G. and Wilhelm, W. E. (2000) 'Strategic, tactical and operational decisions in multi-national logistics networks: A review and discussion of modelling issues', International Journal of Production Research, Vol. 38, $\mathrm{N}^{\circ}$ 7, pp. 1501-1523

Sezen, B. (2008) 'Relative Effect of Design, Integration and Information Sharing on Supply Chain Performance', Supply Chain Manage Int J, Vol. 13, No. 3, pp. 233-240

Simchi-Levi, D., Kaminski, P. and Simchi-Levi, E. (2009) Designing and Managing the Supply Chain: Concepts, Strategies and Case Studies, McGraw-Hill, New York

Straube, F., Ma, S. and Bohn, M. (2008) Internationalisation of Logistics Systems - How Chinese and German Companies Enter New Markets, Springer, Heidelberg

Tracey, M., Lim, J-S. and Vonderembse, M. (2005) 'The Impact of Supply Chain Management Capabilities on Business Performance', Supply Chain Management: An International Journal, Vol. 10, No. 3, pp. 179-191

Yin, R. K. (2013) Case Study Research: Design and Methods, Sage Publications

Zeng, Z. (2003) 'Global Sourcing: Process and Design for Efficient Management', Supply Chain Management: An International Journal, Vol. 8, No. 4, pp. 367-379 